\title{
Attitude and Use of Pentavalent Vaccine among Pregnant Women Attending Antenatal Care in Plateau State Specialist Hospital, Jos, Nigeria
}

\author{
K.C. Okafor, H. O. Isah, J. S. Bimba, S. Thilza, and Z. G. Parah
}

\begin{abstract}
Background: The World Health Organization (WHO) and the Global Alliance for Vaccines and Immunizations (GAVI) recommended the use of Pentavalent vaccines in Nigeria and other developing countries to replace the DPT (Diphtheria, pertusis and tetanus) vaccine. This was done to increase the uptake of the hepatitis $B(\mathrm{Hb})$ and Haemophilus influenza type $b$ (Hib) vaccines in these countries by capitalising on the uptake of DPT vaccine.
\end{abstract}

Objective: This study aims to assess the attitude and use of pentavalent vaccine in pregnant women attending antenatal care in a Tertiary Hospital in Jos, Plateau State, Nigeria.

Methods: The study was carried out among pregnant women receiving antenatal care in Plateau Specialist Hospital, Jos using a descriptive cross sectional study design. The study was done over a period of four (4) months (August 2018 to December 2018). Simple Random Sampling was used to select 397 women who participated in the study.

Results: Respondents were predominantly Christians 283 (71.3\%) wheras Muslims represent about $114(28.7 \%)$ of respondents. About $373(94 \%)$ respondents were married, whereas $24(6.0 \%)$ percent of the respondents were single parents. Also $213(53.7 \%)$ were business women, Only 48 (12.1\%) were civil servants whereas $85(21.4 \%)$ of the respondents had no form of employment. Majority 257 $(97.0 \%)$ of them had a positive attitude towards the vaccine while only a few $8(3.0 \%)$ had a negative attitude.

Eighty eight $(32.2 \%)$ felt pentavalent vaccines were not important. A similar proportion $88(3.2 \%)$ also stated that they would not give their child the vaccine. Most women 252 (95.1\%) agreed that mothers should be encouraged to attend immunization regularly. Side effect experienced by children were fever $69(87.3 \%)$, swelling at injection site $21(26.6 \%)$, rash $6(7.6 \%)$.

Conclusion and recommendations: Almost all pregnant women had a positive attitude towards the vaccine while only a few had a negative attitude. Nine in ten women had children who had received pentavalent vaccine.

Health workers should improve efforts at health education on immunization especially on adverse effects following immunization (AEFI), reasons for missed opportunities,

\section{Published on July 15, 2019}

(Corresponding Author) Okafor Kingsley Chinedu is with the Department of Community Medicine \& Primary Health Care Bingham University, Karu, Nasarwa State, Nigeria (drokaforkingsley@gmail.com).

Isah Haroun. O. , is with the Department of Community Medicine \& Primary Health Care, Bingham University, Karu, Nasarwa State, Nigeria.

(harounisah@yahoo.co.uk)

Bimba J. S. , is with the Department of Community Medicine \&

Primary Health Care, Bingham University, Karu, Nasarwa State, Nigeria. (bimbajs@yahoo.com)

Thilza S., is with the Department of Community Medicine \& Primary

Health Care, Bingham University, Karu, Nasarwa State, Nigeria.

(thilzasma@gmail.com )

Parah Z. G, . is with the Department of Community Medicine \& Primary Health Care Bingham University, Karu, Nasarwa State, Nigeria.

(zeegarba@yahoo.com ) coverage of hard to reach areas or distant areas via special immunization or home visiting to administer vaccine.

Key words- Immunization, Pentavalent vaccine, Pregnant women.

\section{INTRODUCTION}

Immunization represents a remarkably successful and cost-effective means of reducing infectious diseases and thereby reducing morbidity and mortality in infants and children [1]. In Nigeria, the expanded programme on immunization was introduced in 1978 with the aim of improving the health of Nigerian children by eradicating vaccine preventable infectious killer diseases through routine immunization to children less than the age of two years [2].

Pentavalent vaccine was introduced into the Nigerian routine immunization schedule in 2012 with a view to fast track reduction in child mortality in line with the Millennium Development Goal (MDG 4) targets [3]. The vaccine is a combination of five vaccines-in-one that prevents diphtheria, tetanus, whooping cough, hepatitis B and Haemophilus influenza type $b$ all through a single dose [4], [5]. The World Health Organization (WHO) and the Global Alliance for Vaccines and Immunizations (GAVI) recommended the use of Pentavalent vaccines in Nigeria and other developing countries to replace the DPT (Diphtheria, pertusis and tetanus ) vaccine [3],[6]. This was done to increase the uptake of the hepatitis $\mathrm{B}(\mathrm{Hb})$ and Haemophilus influenza type $b(\mathrm{Hib})$ vaccines in these countries by capitalising on the uptake of DPT vaccine [7], [8].

For a child to be fully immunised, that a child should receive four doses of OPV (Oral polio vaccine), three doses of pentavalent vaccines (at 6,10 and 14 weeks) and one dose each of BCG (Bacilli Calmette- Guerin), HEPB 0, MCV (Measles Containing Vaccine) and Yellow Fever [6]. With its introduction, nearly 400,000 cases of haemophilus influenza type B would be prevented with about 27,000 lives saved annually in Nigeria [3], [9].

Factors influencing the attitude of women toward pentavalent vaccines in Nigeria include, religion, availability of the vaccines, cold chain, fear, trust in the system and belief in myths. Religion poses the greatest challenge to the acceptance of immunization especially among the northern Nigerian Muslims. Generally, the Muslim north has the low immunization coverage, the least being $6 \%$ (northwest) and the highest being $44.6 \%$ (southeast). Christians have $24.2 \%$ immunization coverage as compared to only $8.8 \%$ for Muslims [10]. Inadequate cold 
chain equipment, especially in the rural areas due to worn outs cold chain equipment, poor management and maintenance of refrigerators, cold boxes and other cold chain equipment also results in negative attitude of women towards vaccines. In Nigeria, $47 \%$ of the installed solar fridges were broken and $\$ 205,000$ (73.8 million naira) worth of solar equipment remained uninstalled for months [11]. Negative attitude is fuelled by the rejection of selected vaccines/vaccination by parents or religious bodies more especially in the northern part of Nigeria. The reasons for such rejection are include fear, confusion, negative rumour, and incorrect information. Fears regarding routine immunization are expressed in many parts of Nigeria. For example, fathers of partially immunised children in Muslim rural communities in Lagos State see hidden motives linked with attempts by non-governmental organisations (NGOs) sponsored by unknown enemies in developed countries to reduce the local population and increase mortality rates among Nigerians. Belief in a secret immunization agenda is prevalent in Jigawa, Kano and Yobe States, where many believe activities are fuelled by Western countries determined to impose population control on local Muslim communities [12].

Lack of confidence and trust in routine immunization as effective health interventions for tackling childhood diseases appears to be relatively common in many parts of Nigeria [13]. Commonly, immunization is believed to provide at best only partial immunity. The widespread misconception that immunization can prevent all childhood illnesses reduces trust because when, as it must, immunization fails to give such protection, faith is lost in immunization as an intervention, for any and all diseases [14].

Another factor affecting Pentavalent vaccine use is shortage of vaccines and immunization supplies. This is usually due to insufficient funding and late release of funds. In some years, only $61 \%$ of required funds for procurement of vaccines were released, the late release of funds meant that vaccine had to be bought on the spot market at inflated prices. In some instances, no funds were released for vaccines and the funding cycle had only reached the stage of getting the budget approved [15].

For a child to be fully immunized in Nigeria it cost as much as $\$ 226$ (81,360 naira) per child, the most expensive among developing countries [16]. In spite of these huge resources being expended, there has been no significant increase in immunization coverage in the country particularly in Northern Nigeria. The percentage of fully immunized children in Nigeria has marginally increased from $13 \%$ in 2003 to $23 \%$ in 2008 [17] and only slightly increased to $25 \%$ in 2013 [7], [8]. This however raises concerns as to what could be responsible. The percentage coverage is highest in South West $(50 \%)$ and lowest in North West (6\%). North East has about $8 \%$ immunization coverage, while South East has about $44.6 \%$ coverage [18].

But caregivers seem to have positive attitude toward Pentavalent vaccine as a study showed $78.9 \%$ had a positive attitude towards the pentavalent vaccination [19]. Majority (94.9\%) attributed their awareness to the health workers while just $0.3 \%$ attributed it to schools and neighbours. Socioeconomic status like religion, level of education and income also contributes the awareness and attitude towards pentavalent vaccine.

Developed countries with under-five mortality rate of less than 10 in a 1000 have more than $90 \%$ immunization coverage. However, in developing countries with immunization coverage rates below $80 \%$ have under-five mortality rates above 100 in a 1000 [8]. In Nigeria, immunization coverage rate also varies with region; being lowest in the Northern part of the country predisposing children in the North to disseminated tetanus, influenza, tuberculosis, whooping cough and the other killer infectious diseases. The high prevalence of poverty; not only in area of income but also poverty of knowledge, ideas and opportunities is a major contributor to the poor immunization coverage in this region [7]. This study seeks to assess the practice and attitude of pregnant women towards pentavalent vaccine in Northern Nigeria, Jos Plateau state and possibly address any misconceptions about the vaccine with aim at promoting awareness of pentavalent vaccine among these women thereby facilitating immunization coverage in Northern Nigeria. This research work will contribute to the available literature concerning pentavalent vaccine in Plateau state, Northern Nigeria.

This study aims to assess the attitude and usage of pentavalent vaccine in pregnant women attending antenatal care and to identify factors affecting the use of pentavalent vaccine among pregnant women in Plateau Specialist Hospital, Jos, Plateau State, Nigeria.

\section{METHODOLOGY}

This study was done in Jos, Plateau State. Jos which shares boundaries to the west with Bassa LGA, to its North with Toro LGA of Bauchi state, to its East with Jos East LGA and Jos South LGA southward. The Birom tribe are the most predominant, they are both Christians and Muslims in the community. In addition, other ethnic groups could also be found in all parts of the LGA including Anaguta, Mwaghavul, Ngas, Rukuba and Irigwe. Civil service, farming, small scale businesses are the predominant occupation [20], [21]. Plateau Specialist Hospital located along Old Bukuru Road, Jos North, Plateau State. It is a tertiary health care facility rendering specialized services including antenatal care which records about 1,300 new pregnancy visits each year.

The study was carried out among pregnant women receiving antenatal care in Plateau Specialist hospital, Jos North LGA using a descriptive cross sectional study design. The study was done over a period of four (4) months (August 2018 to December 2018). Two months for data collection and one month for analysis and one month for write up of the final work.

Simple Random Sampling was used to select 397 women who participated in the study. The list of all registered women attending ANC at the hospital was used as the sampling frame.

Data was collected using a pre-tested, intervieweradministered questionnaire. The questions included sociodemographic data: which had questions on age, sex. religion, tribe, state, marital status, education, occupation and number of children. Questions on attitude towards pentavalent vaccine had questions like do you think immunization with pentavalent vaccine is important? Would 
you give your child pentavalent vaccine? Should pentavalent

Table I: Socio-demographic Characteristics of Respondents

\begin{tabular}{|c|c|c|}
\hline \multicolumn{3}{|l|}{ Variables } \\
\hline Age of care giver & FREQUENCY & PERCENTAGE \\
\hline $15-24$ & 218 & 54.9 \\
\hline $25-34$ & 108 & 27.2 \\
\hline $35-44$ & 71 & 17.9 \\
\hline TOTAL & 397 & 100 \\
\hline \multicolumn{3}{|l|}{ Level of education } \\
\hline None & 9 & 2.3 \\
\hline Primary & 45 & 11.3 \\
\hline Secondary & 201 & 50.6 \\
\hline Tertiary & 142 & 35.8 \\
\hline \multicolumn{3}{|l|}{ Religion } \\
\hline Christianity & 283 & 71.3 \\
\hline Islam & 114 & 28.7 \\
\hline \multicolumn{3}{|l|}{ Marital status } \\
\hline Single & 24 & 6.0 \\
\hline Married & 373 & 94.0 \\
\hline \multicolumn{3}{|l|}{ Tribe } \\
\hline Berom & 132 & 34.8 \\
\hline Ngas & 118 & 31.1 \\
\hline Hausa & 37 & 9.8 \\
\hline Mwaghavul & 36 & 9.5 \\
\hline Igbo & 34 & 8.9 \\
\hline Bokkos & 24 & 6.3 \\
\hline Fulani & 16 & 4.2 \\
\hline \multicolumn{3}{|l|}{ Occupation } \\
\hline Business & 213 & 53.7 \\
\hline Student & 51 & 12.8 \\
\hline Civil servant & 48 & 12.1 \\
\hline None & 85 & 21.4 \\
\hline \multicolumn{3}{|l|}{ Number of children } \\
\hline 0 & 111 & 28.0 \\
\hline 1 & 104 & 26.2 \\
\hline $2-3$ & 139 & 35.0 \\
\hline$>4$ & 43 & 10.8 \\
\hline
\end{tabular}

$*$ Mean age $=28.4$, Median age $=28.0$

vaccine should not be free? Do you think one dose of pentavalent vaccine is enough? Do you think mothers should be encouraged to attend immunization regularly? Rainfall and distance are good reasons to default immunization? Should side effects experienced when taking pentavalent vaccine be a good reason to stop vaccination? Questions also looked at use of pentavalent which has questions like have your child being immunized with pentavalent vaccine? Was there any side effects experienced?

The data was collected, entered and analyzed using IBM Statistical package for social sciences (SPSS) version 20.0. A total of 7 questions were used to assess the attitude of the caregivers concerning the pentavalent vaccine. A score of 1 was awarded for a correct answer and 0 for a wrong answer. The total attitude score was calculated and converted to percentages and graded as Negative attitude (scores $49.9 \%$ and below) and Positive attitude (Scores $50.0 \%$ and above)

Test of associations were carried out using Chi squared tests for associations between socio-demographic variables such as age, sex, religion, occupation, level of education and number of children and independent variables such as attitude towards- and usage of pentavalent vaccine. The level of significance of all statistical associations was set at $\mathrm{p}<0.05$.

Ethical clearance to conduct this research was obtained from Bingham University Teaching Hospital Research Ethics Committee, while permission to conduct this study was obtained from Plateau State Specalist Hospital Management. Written informed consent was obtained from each respondent before the conduct of interviews after adequate information must have been given to the respondents by the interviewers. Confidentiality and privacy was respected during the course of interview. Participants were treated with dignity and respect. To ensure confidentiality, respondent's serial numbers rather than name were used to identify each respondent. There was no risk of harm or injury to the participants during or after the study is conducted.

Limitations of this study include the fact that responses from respondents were based on self-report and depended on the truthfulness of the respondents. There $s$ a tendency for recall bias especially among the patients that had pentavalent vaccine. Actual choice behaviour is not observed since this was a descriptive research.

\section{RESULTS}

\section{Socio demographic parameters of Respondents}

A total of 379 participants participated in the study, shows that $218(54.9 \%)$ respondents were within the age range of 15-24 years. In addition to this, (27.2\%) of the respondents were within the age range of 25-34 years. Only $(17.9 \%)$ were aged $35-44$ years.

Table I also shows, that $142(35.8 \%)$ of the respondents are graduates of tertiary institutions, 201 (50.6\%) of the respondents were secondary school graduates, $45(11.3 \%)$ have primary school education. It also shows that the respondents were predominantly Christians 283 (71.3\%) while Muslims represent about 114 (28.7\%) of respondents. Marital status shows that $373(94 \%)$ respondents were married, While $24(6.0 \%)$ percent of the respondents were single parents. Also 213 (53.7\%) were business women, Only $48(12.1 \%)$ were civil servants while $85(21.4 \%)$ of the respondents had no form of employment. Most respondents were 113 (34.8\%) Berom, 118 (31.1\%), 37 (9.8\%), Mwaghvu , 36 (9.5\%), Igbo 34 (8.9\%). More respondents were business women 213 (53.7\%), 51 (12.8\%) were students, $48(12.1 \%)$ were civil servants.

\section{B) Attitude of respondents towards Pentavalent vaccines}

Table II shows the attitude of the respondents towards pentavalent vaccine. Majority 257(97.0\%) of them had a positive attitude towards the vaccine while only a few 
$8(3.0 \%)$ had a negative attitude.

Eighty eight $(32.2 \%)$ felt pentavalent vaccines were not important, while $177(66.8 \%)$ felt it was important, A similar proportion $88(3.2 \%)$ also stated that they would not give their child the vaccine, while $177(66.8 \%)$ agreed to give their child the vaccine. Majority of respondents 210 (79.2\%) asserted that the vaccine should be free, while 55 (20.8\%) said it should not be free. Most women 201 (75.8\%) knew that one dose of the vaccine was not enough while $24.2 \%$ felt one dose is sufficient. Most women 252 (95.1\%) agreed that mothers should be encouraged to attend immunization regularly, while 13 (4.9\%) did not agree. A higher proportion of women felt that rainfall and distance are good reasons to default from routine immunization, while $38(14.3 \%)$ felt rainfall and distance are not good reasons to miss routine immunization. Most women 219 $(82.6 \%)$ felt experiencing a side effect is a good reason to stop vaccination, while $46(17.4 \%)$ stated that side effect is not a good reason to stop vaccination.

Table III shows the relationship between sociodemographic factors and attitude towards the pentavalent vaccine. There was statistically significant association between occupation of women and attitude toward pentavalent vaccines $(\mathrm{p}=0.021)$. More women who had no occupation $5(9.4 \%)$ had negative attitude towards pentavalent vaccine than those who were business women 2 (1.5\%).

There was a statistically significantly association between religion and the attitude towards the vaccine $(\mathrm{p}=0.034)$. More Christians 185 (98.4\%), than Muslims 72(93.5\%) had a positive attitude towards pentavalent vaccines.

Majority $156(97.5 \%)$ of respondents with positive attitude were between between 25-34 years of age, more women aged $15-24$ years $3(6.2 \%)$ had negative attitude towards pentavalent vaccine than older women $35-44$ years with $1(1.8 \%)$ and this relationship was not statistically significant $(\mathrm{p}=0.338)$.

The level of education did not significantly affect the attitude towards the vaccine with the highest being among those with secondary level of education, 125 (96.2\%). The association between these two variables was not statistically significant $(\mathrm{p}=0.714)$.

Married respondents constituted a high proportion, 248 $(96.9 \%)$ of respondents with a positive attitude. The association between marital status and attitude toward the pentavalent vaccine was not statistically significant $(\mathrm{p}=$ 0.590).

\section{Usage of pentavalent vaccine among pregnant women attending antenatal care}

Table IV shows almost all women 279 (97.6\%) had children who had received pentavalent vaccine, 7 (2.4\%) had not had children who were given pentavalent vaccines. Mothers whose children did not receive the vaccines did so due to unavailability $3(42.9 \%)$ and inconvenient time 4 $(57.1 \%)$. Most women $200(71.7 \%)$ reported that their children did not experience any side effects after administration of pentavalent vaccines, while $79(28.3 \%)$ reported side effects on their children after pentavalent vaccination. Side effect experienced by children were fever $69(87.3 \%)$, swelling at injection site $21(26.6 \%)$, rash 6
$(7.6 \%)$.

Table V shows the relationship between sociodemographic factors and usage of pentavalent vaccine. All women $35-44$ years $66(100.0 \%)$ had used the vaccine, while $34(94.4 \%)$ of women $15-24$ years of age had use the pentavalent vaccine, although the relationship between age of respondents and usage of the vaccine was not statistically significant with $\mathrm{p}=0.205$.

\begin{tabular}{|c|c|c|}
\hline $\begin{array}{l}\text { Table II: Attitude towar } \\
\text { Respondents }\end{array}$ & ntavalent & ne among \\
\hline $\begin{array}{l}\text { Variables } \\
\text { Frequency } n=265\end{array}$ & Yes (\%) & No $(\%)$ \\
\hline $\begin{array}{l}\text { Pentavalent vaccine is } \\
\text { important }\end{array}$ & $177(66.8)$ & $88(32.2)$ \\
\hline Would you give your child & $177(66.8)$ & $88(32.2)$ \\
\hline $\begin{array}{l}\text { Pentavalent vaccine should } \\
\text { not be free }\end{array}$ & $55(20.8)$ & $210(79.2)$ \\
\hline One dose is enough & $201(75.8)$ & $64(24.2)$ \\
\hline $\begin{array}{l}\text { Mothers should be } \\
\text { encourage to attend } \\
\text { immunization regularly }\end{array}$ & $252(95.1)$ & $13(4.9)$ \\
\hline $\begin{array}{l}\text { Rainfall and distance are } \\
\text { good reason to default } \\
\text { immunization }\end{array}$ & $227(85.7)$ & $38(14.3)$ \\
\hline $\begin{array}{l}\text { Side effect experience is a } \\
\text { good reason to stop } \\
\text { vaccination }\end{array}$ & $219(82.6)$ & $46(17.4)$ \\
\hline $\begin{array}{l}\text { Overall attitude toward } \\
\text { Pentavalent Vaccine }\end{array}$ & & \\
\hline Negative & $8(3.0)$ & \\
\hline Positive & $257(97.0)$ & \\
\hline Total & $265(100.0)$ & \\
\hline
\end{tabular}

Majority 197(97.5\%) of those that had used the vaccine were Christians, although the relationship was not statistically significant with $\mathrm{p}=0.963$.

There was a statistically significant association between marital status of the respondent and use of pentavent vaccine with $\mathrm{p}=0.0001$ and majority of those that had used the vaccine were married women with a number of $276(98.6 \%)$ while single women $3(50.0 \%)$ had used the vaccine.

\section{DISCUSSION}

There was a positive attitude towards pentavalent vaccine in a majority of respondents; this is similar to a study carried out in Lagos [22] which showed that $96.6 \%$ of women had a positive attitude towards immunization. Despite this impressive level of positive attitude, a third felt pentavalent vaccine were not important, a similar proportion (a third) also stated that they would not give their child the vaccine. This finding presents a difficult situation that can lead to rejection of vaccines in the community. Continuous advocacy and education is vital in making sure that women are willing to take their children to get immunization. The positive attitude as revealed in this study is an opportunity for the public health system to implement routine immunization in full scale so as to increase immunization coverage in Nigeria. 
It is important to note that the high positive attitude towards pentavalent vaccine may be due to most of the women agreed that mothers should be encouraged to attend immunization regularly. In contrast, a higher proportion of women felt that rainfall and distance are good reasons to default from routine immunization. This erroneous reason may be responsible for the low coverage in Nigeria [23]. Parents and care givers should continue to support immunization and listen to health workers during health education session.

Table III: Socio-demographic characteristics of respondents and attitude towards pentavalent vaccine

\begin{tabular}{|c|c|c|c|}
\hline Variable & Positive & Negative & $\begin{array}{c}\text { Test } \\
\text { statistics }\end{array}$ \\
\hline $\begin{array}{l}\text { Age group } \\
\text { (years) }\end{array}$ & & & \\
\hline $15-24$ & $45(93.8 \%)$ & $3(6.2 \%)$ & $\mathrm{X} 2=2.17$ \\
$25-34$ & $156(97.5 \%)$ & $4(2.5 \%)$ & $\mathrm{p}=0.338$ \\
$35-44$ & $56(98.2 \%)$ & $1(1.8 \%)$ & \\
& & & \\
\hline Religion & & & \\
\hline Christianity & $185(98.4 \%)$ & $3(1.6 \%)$ & $\mathrm{X} 2=4.476$ \\
Islam & $72(93.5 \%)$ & $5(6.5 \%)$ & $\mathbf{p}=\mathbf{0 . 0 3 4}$ \\
\hline Marital status & & & \\
\hline Single & $9(100.0 \%)$ & $0(0.0 \%)$ & $\mathrm{X} 2=0.290$ \\
Married & $248(96.9 \%)$ & $8(3.1 \%)$ & $\mathrm{p}=0.590$ \\
\hline Occupation & & & \\
\hline Business & $140(98.6 \%)$ & $2(1.4 \%)$ & $\mathrm{X} 2=9.723$ \\
Student & $32(100.0 \%)$ & $0(0.0 \%)$ & $\mathbf{p}=\mathbf{0 . 0 2 1} *$ \\
Civil servant & $37(97.4 \%)$ & $1(2.6 \%)$ & \\
None & $48(90.6 \%)$ & $5(9.4 \%)$ & \\
& & & \\
\hline Number of & & & \\
children & & & \\
\hline 0 & $38(97.4 \%)$ & $1(2.6 \%)$ & $\mathrm{X} 2=0.367$ \\
1 & $86(97.7 \%)$ & $2(2.3 \%)$ & $\mathrm{p}=0.947$ \\
$2-3$ & $106(96.4 \%)$ & $4(3.6 \%)$ & \\
\hline 4 & $27(96.4 \%)$ & $1(3.6 \%)$ & \\
\hline
\end{tabular}

Occupation and religion plays an important role in the attitude of respondents, as there was statistically significant association between occupation of women and attitude toward pentavalent vaccines. More women who had no occupation had negative attitude towards pentavalent vaccine than those who had occupation. The lower positive attitude here may not be unconnected to the rumour in the Northern part of Nigeria, that vaccines were made to make women less fertile and has so many side effect. Efforts must be made to reorient the people against this postulation. The churches and mosques are good areas for advocacy to increase utilization of immunization services.

Majority of the mothers had used pentavalent vaccine; this is different from a study carried out in Plateau state [21] which revealed that fewer than one-third of the mothers had fully immunized children. This may be due to fact that the vaccine is given at no cost. Findings is similar to a study carried out in Lagos [22] which found that $86 \%$ of the respondents reported completing their doses of penatavalent vaccine. This high level of immunization coverage is essential in combating disease in the State and also offers better protection for the children.

This study corroborates the statement as over three quarters of respondents asserted that the vaccine should be free. This is to increase coverage. The positive attitude towards pentavalent vaccines was demonstrated in its use. Most women in this study agreed that mothers should be encouraged to attend immunization regularly but they felt experiencing a side effect is a good reason to stop vaccination. This calls for health education targeting Adverse effects following immunization (AEFI).

Uptake of vaccination services is dependent not only on provision of routine immunization services but also on other factors including attitude of mothers towards immunization [13], [24]. density of health workers [16] accessibility to vaccination clinics and availability of safe needles and syringes [25].

\section{OVERALL ATTITUDE}

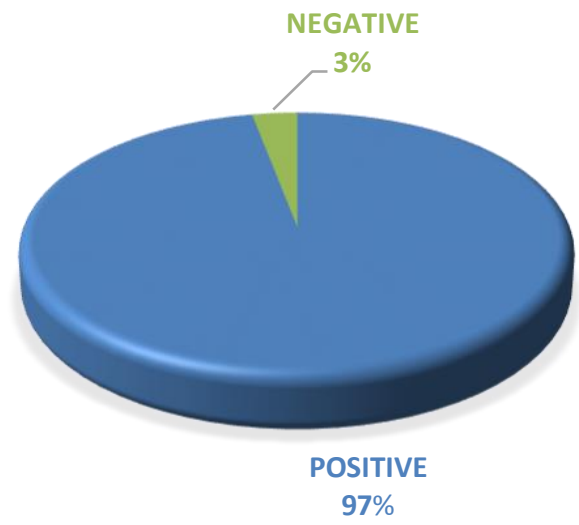

Figure 1: Pie chart showing the attitude of respondents to pentavalent vaccines

\section{CONCLUSION}

All most all pregnant women (97.0\%) had a positive attitude towards the vaccine while only a few (3.0\%) had a negative attitude. A third felt pentavalent vaccine were not important, a third would not give their child the vaccine. A higher proportion of women felt that rainfall, long distance and experiencing side effects are good reasons to default from routine immunization. Occupation and religion had statistically significant association with attitude toward pentavalent vaccines.

Almost all women (97.6\%) had children who had received pentavalent vaccine, while only $2.4 \%$ had not had children who were given pentavalent vaccines. Those children did not receive due to unavailability and inconvenient time. A fourth reported side effects on their children after pentavalent vaccination. These side effect experienced by children were fever swelling at injection site, rash.

\section{RECOMMENDATION}

The Government should make it mandatory for children 
to present their immunization cards before being admitted into public and private schools in order to increase use of pentavalent vaccines and routine immunization. Health workers should improve efforts at health education on immunization especially on adverse effects following immunization (AEFI), reasons for missed opportunities, heath workers and facilities should improve coverage of hard to reach areas or distant areas via special immunization or home visiting to administer vaccine. Pregnant women should increase attendance at immunization services as offered by the health facilities.

\section{Table IV: Usage of pentavalent vaccine among} pregnant women attending antenatal care

\begin{tabular}{|c|c|c|}
\hline Variable Frequency & $\begin{array}{l}\text { Percentage } \\
(\%)\end{array}$ \\
\hline $\begin{array}{l}\text { Child has received } \\
\text { pentavalent vaccine }\end{array}$ & $\mathbf{n = 2 8 6}$ & \\
\hline Yes & 279 & 97.6 \\
No & 7 & 2.4 \\
Total & 286 & $100 \%$ \\
\hline If no, why? & $\mathrm{n}=7$ & \\
\hline $\begin{array}{l}\text { Inconvenient time } \\
\text { Unavailable vaccine }\end{array}$ & 4 & 57.1 \\
\hline Experienced side effects & $\mathrm{n}=286$ & 42.9 \\
\hline Yes & 79 & 28.3 \\
No & 200 & 71.7 \\
\hline Side effects* & 69 & 87.3 \\
\hline Fever & 21 & 26.6 \\
\hline Swelling at injection site & 6 & 7.6 \\
\hline Rash & \multicolumn{2}{|l}{} \\
\hline *Multiple responses given \\
286 respondents had at least a child.
\end{tabular}

\begin{tabular}{|c|c|c|c|}
\hline Variable & Yes & No & $\begin{array}{c}\text { Test } \\
\text { statistics }\end{array}$ \\
\hline \multicolumn{4}{|l|}{$\begin{array}{l}\begin{array}{l}\text { Age } \\
\text { (years) }\end{array} \\
\end{array}$} \\
\hline $\begin{array}{l}15-24 \\
25-34 \\
35-44\end{array}$ & $\begin{array}{c}34(94.4 \%) \\
179(97.3 \%) \\
66(100.0 \%)\end{array}$ & $\begin{array}{l}2(5.6 \%) \\
5(2.7 \%) \\
0(0.0 \%)\end{array}$ & $\begin{array}{l}X 2=3.168 \\
p=0.205\end{array}$ \\
\hline \multicolumn{4}{|l|}{ Religion } \\
\hline $\begin{array}{l}\text { Christianity } \\
\text { Islam }\end{array}$ & $\begin{array}{r}197(97.5 \%) \\
82(97.6 \%)\end{array}$ & $\begin{array}{l}5(2.5 \%) \\
2(2.4 \%)\end{array}$ & $\begin{array}{l}X 2=0.002 \\
p=0.963\end{array}$ \\
\hline \multicolumn{4}{|l|}{ Marital status } \\
\hline $\begin{array}{l}\text { Single } \\
\text { Married }\end{array}$ & $\begin{array}{c}3(50.0 \%) \\
276(98.6)\end{array}$ & $\begin{array}{r}3(50.0 \%) \\
4(1.4 \%) \\
\end{array}$ & $\begin{array}{l}X 2=58.041 \\
\mathbf{p}=\mathbf{0 . 0 0 0 1} *\end{array}$ \\
\hline \multicolumn{4}{|l|}{$\begin{array}{l}\text { Number of } \\
\text { children }\end{array}$} \\
\hline $\begin{array}{l}1 \\
2-3 \\
>4\end{array}$ & $\begin{array}{l}100(96.2 \%) \\
136(97.8 \%) \\
43(100.0 \%)\end{array}$ & $\begin{array}{l}4(3.8 \%) \\
3(2.2 \%) \\
7(2.4 \%)\end{array}$ & $\begin{array}{l}X 2=1.980 \\
p=0.372\end{array}$ \\
\hline
\end{tabular}

\section{REFERENCES}

[1] Azubuike, J.C, Nkanginieme, K.E.O . Paediatrics and Child Health in a Tropic Region. 2nd Edition. African Educational Services Owerri.2007. 34 - 45

[2] Federal Ministry of Health. National Immunization Policy . National Primary Health Care Development Agency. NPHCDA; 2009. 7-9.

[3] WHO, UNICEF, World Bank. State of the world's vaccines and immunization, 3rd ed. Geneva, World Health Organization. .2009. Accessed 26/3/2014.

[4] Nigerian Immunization Schedule. http://www.mamalette.com accessed 15/08/2015.

[5] Sadoh A.E, Nwaneri D.U, Ogboghodo B.C, Sadoh W.E.. Effect of introduction of pentavalent vaccine as replacement for DiphtheriaTetanus-Pertussis and Hepatitis B vaccines on vaccination uptake in a health facility in Nigeria. 2016. 34(24):2722-8. doi: 10.

[6] World Health Organization . Nigeria launches Pentavalent vaccine. WHO Regional office for Africa, Brazzaville. 2012 Available from http://www.afro.who.int/en/nigeria/press-materials/ item/4735nigeria-launchespenta-vaccine.html. Accessed 26/3/2014.

[7] Obasohan P.E., Anosike B.U and Etsunyakpa M.B. . Determinant of Full Immunization Coverage and Reasons for its Failure for Children in Bida Emirate Area, Niger State, Nigeria. Merit Research Journal of Medicine and Medical Sciences; 2015 3(10), 476-483.

[8] Obasohan P.E et al.. Knowledge, Attitude and Practice of Immunization Processes and its Coverage in Rural Communities of Bida Emirate Area, Niger State, Nigeria. ARC Journal of Nursing and Healthcare. 2015 Vol 1:1. 29-37.

[9] Block S. L. . Community-wide vaccination with the heptavalent pneumococcal conjugate significantly alters the microbiology of acute otitis media. Pediatr. Infect. Dis. J. 2007. 23:829-833.

[10] Ankrah V, Nwaigwe F.. Immunization system review and training needs assessment in Ekiti State. February. Ado - Ekiti Ministry of Health. PATHS;2005

[11] Yahya M. Polio vaccines 'no thank you' barriers to polio eradication in Nothern Nigeria. Afr Aff; 2007.106(423): 185-204.

[12] Yola A.W. Report on Child Immunization Clusters (CICS); BMJ. 2003.4: $1-3$.

[13] Babalola S, Adewuyi A. Factors Influencing Immunization Uptake in Nigeria: A Theory-based Research in Six States. Abuja: PATHS. 2005.

[14] Brieger W.R, Salami K.K, Ogunlade B.P. Catchment Area Planning and Action: Documentation of the Community-based Approach in Nigeria. Arlington: Va.: BASICS II For USAID. 2004.

[15] Kaufmann J.R, Feldbaum H. Diplomacy and the polio immunization boycott in Northern Nigeria. Health Aff; 2009. 28: 1091-1101.

[16] Antai D . Rural-Urban Inequalities in Childhood Immunization in Nigeria: The Role of Community Contexts; African Journal of Primary Health Care and Family Medicine, 2011.Vol. 3, No 1. 12 23.

[17] Sanou A, Simboro S, Kouyaté K, Dugas M, Graham J and Bibeau G (2009). Assessment of factors associated with complete immunization coverage in children aged 12-23 months: a cross-sectional study in Nouna district, Burkina Faso; BMC International Health and. Human $\begin{array}{llllll}\text { Right. 2009. } & 9 & \text { (S1):S } 10 . \quad \text { Available http:// }\end{array}$ www.biomedcentral.com/1472-698X/9/S1/S10

[18] Ophori E.A, Tula M.Y, Azih A.V, Ikpo P.E. Current trends of immunization in Nigeria: prospect and challenges. Tropical medical health; 2016. 42(2): 67-75.

[19] Ogboghodo E.O, Esene H.A, Okojie O.H. . Determinants of uptake of pentavalent vaccine in Benin City, Southern Nigeria. Int J Community Med Public Health; 2016. 3:3195-201.

[20] Nanzip B.N. Jos North Local Govenment Area, Jos Plateau State. 2017 www.jotscroll/com.

[21] Chris-Otubor, G.O., Dangiwa, D.A., Ior, L.D, Anukam, N.C. Assessment of Knowledge, Attitudes and Practices of Mothers in Jos North Regarding Immunization. IOSR Journal Of Pharmacy (e)ISSN: 2250-3013, (p)-ISSN: 2015. 2319-4219 www.iosrphr.org Volume 5 , .

[22] Odia O.J, Okafor I.P, Roberts A.A. . Knowledge, Attitude and Practice of Childhood Immunization among Mothers of Under-Fives in Kosofe Local Council Development Area, Lagos State. Journal of Community Medicine and Primary Health Care. 2013. 27 (1) 55-63.

[23] National Population Commission (NPC) and ICF International. 2014 Nigeria Demographic and Health Survey 2013. Abuja, Nigeria, Rockville, Maryland, USA: NPC and ICF International.

[24] Mutua M.K, Kimani-Murage E, Ngomi N, Ravn H, Mwaniki P, Echoka E. . Fully immunized child: coverage, timing and sequencing of routine immunization in an urban poor settlement in Nairobi, Kenya. Trop Med Health. 2016 .16;44:13. doi: 10.1186/s41182. 
[25] Oluwadare C.The Social determinant of routine immunization in Ekiti State of Nigeria. Ethno-Med; 2009. 3(1): 49-56.

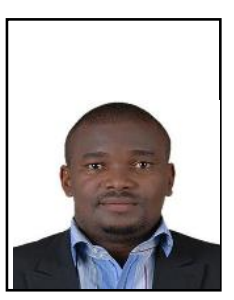

1.Okafor Kingsley Chinedu (Corresponding Author)

Consultant Community Health Physician

MBBS, MPH, MPA, MHPM, FWACP (Comm Health)

Department of Community Medicine \& Primary Health Care

Bingham University, Karu, Nasarwa State

drokaforkingsley@gmail.com , +234 (0)81866 86646

2. Isah Haroun. O,

MBBS, MPH, FWACP, FIMC, CMC

Associate Professor/ Consultant Public Health Physician

Department of Community Medicine \& Primary Health Care

Bingham University, Karu, Nasarwa State.

harounisah@yahoo.co.uk

\section{Bimba J.S,}

Lecturer/ Consultant Community Health Physician

Department of Community Medicine \& Primary Health Care

Bingham University, Karu, Nasarwa State.

bimbajs@yahoo.com

\section{Thilza $S$,}

Lecturer/ Consultant Community Health Physician

Department of Community Medicine \& Primary Health Care Bingham University, Karu, Nasarwa State.

thilzasma@gmail.com

\section{Parah Z. G}

Department of Community Medicine \& Primary Health Care

Bingham University, Karu, Nasarwa State.

zeegarba@yahoo.com 